\title{
DE WET OP HET SCHADEVERZEKERINGSBEDRIJF
}

door G. A. Koelman

Par. 1. Inleiding en strekking der wet

Par. 2. Het systeem van toezicht

Par. 3. Enkele belangrijke bepalingen uit de wet

Par. 4. Enige voor de controlerende accountant belangrijke facetten van het schadeverzekeringsbedrijf

\section{Par. 1. INLEIDING EN STREKKING DER WET}

Mede in verband met de ervaringen in de tweede wereldoorlog opgedaan, werd reeds in 1945 een wetsontwerp op de buitenlandse verzekeringsmaatschappijen aan een door de Minister van Financiën ingestelde commissie voor het schadeverzekeringsbedrijf voorgelegd. Deze commissie adviseerde toen afwijzend, doch verklaarde zich akkoord met wettelijke maatregelen voor zowel binnen- als buitenlandse maatschappijen. In nauwe samenwerking met deze commissie is de regering tot een wetsontwerp gekomen, welk ontwerp d.d. 26 oktober 1961, een maand na het aanvragen van surséance van betaling door de N.V. Assurantiemaatschappij „Brandaris”, bij de Tweede Kamer werd ingediend.

$\mathrm{Na}$ enige kleine wijzigingen heeft de Eerste Kamer op 22 september 1964 het ontwerp van de wet op het schadeverzekeringsbedrijf aanvaard.

Blijkens art. 57 van deze wet zal de datum van inwerkingtreding nog nader worden vastgesteld, hetgeen tot dusverre nog niet heeft plaatsgevonden.

Uit de memorie van toelichting op het ontwerp van de wet blijkt o.m. dat de regering het toezicht van belang acht:

a. ter voorkoming van ernstig nadeel voor het bedrijfsleven tengevolge van déconfitures van schadeverzekeringsmaatschappijen;

b. ter vermijding van aantasting van het vertrouwen van het publiek in het schadeverzekeringsbedrijf.

\section{Par. 2. HET SYSTEEM VAN TOEZICHT}

Bij bestudering van de vraag, van welke principes het toezicht diende uit te gaan, heeft de regering zich verdiept in de verschillende toezichtstelsels, die hier te lande en elders worden toegepast. Het bleek haar daarbij, dat in het algemeen drie toezichtsystemen worden onderscheiden, t.w.:

a. het publiciteitsysteem (uitgaande van de gedachte dat kan worden volstaan met de voorgeschreven publicatie van bepaalde financiële en zonodig andere gegevens);

b. het systeem der normatieve voorschriften (het voorschrijven van normen, waaraan de ondernemingen die het bedrijf willen uitoefenen moeten voldoen, waarbij gewoonlijk ook de publicatie van gegevens wordt geëist);

c. het materiële systeem (geeft voorschriften die ingrijpen in het bedrijfsbeleid der maatschappijen).

De regering heeft geopteerd voor het systeem der normatieve voorschriften aangevuld met elementen van het materiële systeem, omdat zij meent dat daarmede in de Nederlandse verhoudingen voldoende waarborgen worden geschapen voor 
de verzekeringnemers, de verzekerden en de gelaedeerden en tevens een zo groot mogelijke vrijheid wordt gelaten aan het bedrijfsleven.

De aanvulling met elementen van het materiële systeem heeft in hoofdzaak betrekking op de invoering van het adviesrecht. De toezichthouder behoeft daarbij niet lijdelijk toe te zien, doch heeft de gelegenheid om bij een ongunstige ontwikkeling of geconstateerde fouten, welke of wel een onderneming in haar bestaan zouden kunnen bedreigen, of ten nadele zouden strekken van verzekeringnemers en verzekerden, de betrokken onderneming te adviseren over de te volgen gedragslijn. Deze onderneming is dan vrij de oplossing te kiezen die haar als de meest juiste voorkomt en, ingeval zij het niet eens is met het advies, dit te negeren. Zij loopt daarbij echter de kans, dat het advies wordt gepubliceerd, met alle gevolgen van dien.

\section{Par. 3. ENKELE BELANGRIJKE BEPALINGEN UIT DE WET}

In het hiernavolgende worden enige belangrijke bepalingen uit de wet beknopt weergegeven.

\section{A. Eisen voor Nederlandse ondernemingen}

Art. 9.1. Het schadeverzekeringsbedrijf mag alleen worden uitgeoefend door naamloze vennootschappen en onderlinge waarborgmaatschappijen.

Art. 12.1. Een naamloze vennootschap of een onderlinge waarborgmaatschappij met een in aandelen verdeeld waarborgkapitaal mag het schadeverzekeringsbedrijf slechts uitoefenen, indien haar geplaatste maatschappelijk of waarborgkapitaal tenminste één miljoen gulden bedraagt en van dit bedrag tenminste een tiende gedeelte is gestort.

Art. 13.1. Bij elke onderneming moeten extra waarborgen aanwezig zijn, welke berekend overeenkomstig bij algemene maatregel van bestuur te stellen regelen, tenminste tien percent van de geboekte brutopremie gedurende het voorgaande boekjaar bedragen.

\section{$B$. Eisen voor buitenlandse ondernemingen}

Deze eisen komen in grote lijnen overeen met die, welke voor Nederlandse ondernemingen zijn gesteld.

\section{Het toezicht}

Art. 22.1. Het toezicht berust bij de Verzekeringskamer.

Art. 22.1. Iedere onderneming is verplicht het boekjaar te doen lopen van 1 januari $\mathrm{t} / \mathrm{m} 31$ december.

Art. 23.1. Iedere onderneming is verplicht jaarlijks een verslag op te maken en ter beschikking van verzekerden te stellen.

Art. 24.1. Iedere onderneming is verplicht bij de verzekeringskamer periodiek binnen de door deze vastgestelde termijnen staten in te dienen, welke naar waarheid moeten zijn ingevuld en tezamen een duidelijk en volledig beeld moeten geven van het door de onderneming gevoerde beheer en van haar financiële toestand.

2. Iedere onderneming is gehouden de staten vergezeld te doen gaan van een verklaring van een accountant, waaruit blijkt, dat deze door hem zijn onderzocht en akkoord bevonden en ten bewijze daarvan door hem zijn gewaarmerkt. 
6. De modellen van de staten en van de accountantsverklaring worden bij algemene maatregel van bestuur vastgesteld. Daarbij wordt tevens bepaald, welke staten, vergezeld van de accountantsverklaring, in het in art. 23.1. bedoelde verslag moeten worden opgenomen.

Art. 27. Iedere onderneming is verplicht aan de verzekeringskamer binnen de door deze te bepalen termijn, naar waarheid de inlichtingen te verstrekken, welke deze voor de vervulling van de haar bij en krachtens deze wet opgelegde taak mocht verlangen.

Art. 28. De verzekeringskamer is bevoegd getuigen en deskundigen op te roepen. Art. 29. De verzekeringskamer is bevoegd inzage te nemen of te doen nemen van boeken en bescheiden van een onderneming.

Art. 30. De verzekeringskamer is bevoegd aan een onderneming adviezen te geven.

Uit bovenstaande artikelen blijkt, dat de staten (gewaarmerkt door een accountant), welke periodiek bij de verzekeringskamer moeten worden ingediend, de basis voor de uitoefening van het toezicht vormen.

Indien de staten daartoe aanleiding geven zal de verzekeringskamer onmiddellijk tot zelfstandig onderzoek overgaan, met de haar daartoe ten dienste staande middelen, zoals:

- inlichtingen vragen;

- getuigen en deskundigen oproepen;

- inzage in boeken en bescheiden nemen.

\section{Par. 4. ENIGE VOOR DE CONTROLERENDE ACCOUNTANT BELANG- RIJKE FACETTEN VAN HET SCHADEVERZEKERINGSBEDRIJF}

In de wet is verplicht gesteld dat zowel de jaarrekening als de periodiek in te dienen staten door een accountant worden gewaarmerkt. De activiteiten van de schadeverzekeringsmaatschappijen vertonen een grote verscheidenheid, zo ook, mede hierdoor veroorzaakt, de normen en begrippen welke bij de opstelling van de jaarrekeningen worden gehanteerd.

De controlerende accountant geeft met een goedkeurende verklaring aan, dat de basis voor het uitoefenen van het toezicht door de verzekeringskamer betrouwbaar is.

Het lijkt daarom niet alleen gewenst, doch zelfs noodzakelijk, dat zowel ten aanzien van de normen en begrippen welke bij de opstelling van de jaarrekeningen en de staten worden gehanteerd, als ook ten aanzien van de controle-opvattingen met betrekking tot de essentiële onderdelen der jaarrekening, bij de accountants een eenheid van opvatting bestaat.

Onderstaande onderwerpen geven slechts de naar mijn mening belangrijke facetten waaromtrent verschil van inzicht zou kunnen bestaan. Het aansnijden van deze onderwerpen heeft de bedoeling op deze wijze tot een gedachtenwisseling te komen, opdat de hierboven bedoelde eenheid van opvatting zal worden gerealiseerd.

\section{Premie en voorziening onverdiende jaarpremie}

1. De langzamerhand in vele bedrijfstakken toegepaste onderscheiding in 
„,reserve” en „voorziening” dient ook bij de schadeverzekeringsbedrijven te worden geadviseerd.

In een brochure uitgegeven door de Raad van Nederlandse Werkgeversverbonden getiteld „Verslaggeving, Verantwoording en Voorlichting”, wordt deze onderscheiding in ,reserves" en ,,voorzieningen” ook aanbevolen. In deze onderscheiding vormen reserves een bestanddeel van het eigen vermogen, terwijl voorzieningen een schatting van niet vaststaande verplichtingen vormen, dan wel een zo goed mogelijke benadering van aanwezige risico's.

„Premiereserve” zou dienen te worden vervangen door ,,voorziening onverdiende jaarpremie". De onverdiende jaarpremie vormt immers op de balansdatum, uitgaande van de gedachte dat:

a. het bedrijf niet wordt voortgezet, een benadering van de verplichting tot premierestitutie aan de verzekerden;

$b$. het bedrijf wordt voortgezet, een schatting van niet vaststaande verplichtingen, of wel een voorziening om hieruit de schaden, gevallen in het nieuwe jaar tussen balansdatum en premievervaldag op verzekeringen waarvan de premie in het voorgaande jaar werd ontvangen, te betalen.

2. De belangrijkste in de praktijk voorkomende systemen ter vaststelling van de „voorziening onverdiende jaarpremie" zijn:

a. $40 \%$ van de in een jaar geboek te bruto premie eigen behoud;

b. het $1 / 24$-systeem.

Ad a. Dit systeem berust op de volgende veronderstellingen:

1 e. er is sprake van een volkomen gelijkmatige verdeling van het premie-inkomen over het jaar, zodat een gemiddelde vervaldag van 1 juli kan worden aangenomen;

2e. er is sprake van een commissiepercentage van $20 \%$;

3e. het betreft alleen jaarposten.

Uitgaande van het principe dat de jaarrekening een juist beeld dient te geven van de vermogenstoestand en de behaalde resultaten en derhalve zowel een te lage als een te hoge voorziening een onjuist beeld kan geven, is over bovengenoemde veronderstellingen het volgende op te merken:

ad 1e. Een volkomen gelijkmatige verdeling over het jaar zal slechts bij uitzondering voorkomen, een wijziging in de bedrijfsomvang (toe- of afname van de portefeuille) zou dan ook gelijkmatig over het jaar moeten zijn verdeeld. Een berekening op basis van het z.g. 1/24-systeem op nettopremiebasis zal dan ook meestal een juistere uitkomst geven;

ad $2 e$. De commissie zal meestal hoger dan $20 \%$ zijn, waardoor op basis van $40 \%$ bruto een te hoge voorziening wordt becijferd. Een berekening op basis van netto-premie maakt zich los van deze $20 \%$ commissie-veronderstelling en zal dus dienen te worden geprefereerd;

ad $3 e$. De veelal toegepaste redenering dat de op basis van $40 \%$ bruto becijferde voorziening te hoog is voor jaarposten en korte termijnposten doch dan voorziet in de noodzakelijke extra voorziening voor meerjaarsposten, dient, ook al zou in een bepaald geval sprake zijn van gelijkwaardigheid van beide componenten, als algemeen uitgangspunt te worden afgewezen.

Ten aanzien van de meerjaarsposten dient de techniek als hieronder in punt 3 aangegeven te worden gevolgd. 
Ad $b$. Het $1 / 24$-systeem is een verfijning van de veronderstelling dat de gemiddelde vervaldag op 1 juli ligt, nl. een verfijning per maand.

Van de jaarposten vervallende in januari wordt verondersteld dat de gemiddelde vervaldag op 15 januari ligt, waarvan op 31 december derhalve $1 / 24$ onverdiend is en $23 / 24$ verdiend;

van de posten van februari $3 / 24$ onverdiend en $21 / 24$ verdiend, enz.

Daar het 1/24-systeem geen veronderstellingen ten aanzien van het commissiepercentage inhoudt, aangezien er op basis van de nettopremie wordt gerekend, en het rekenkundig een vrij nauwkeurige benadering van de onverdiende premie geeft, verdient dit systeem de voorkeur.

3. Er worden verzekeringen afgesloten, waarbij de premie voor meerdere jaren bij de afsluiting ineens wordt voldaan, z.g. meerjaarsposten. Voor een juiste presentatie in de jaarrekening, met name ten aanzien van de samenstelling van het resultaat is het voor meerjaarsposten gewenst, om niet de in het jaar ontvangen premie ten gunste van de resultatenrekening te brengen, doch slechts de in het jaar , vervallende" jaarpremiegedeelten.

De „vooruitontvangen” jaarpremiegedeelten dienen dan als ,onverdiende jaarfracties van meerjaarsposten" gepassiveerd te worden. Uit deze voorziening wordt jaarlijks een jaarfractie vrijgenomen en als premie in de resultatenrekening verantwoord. Hetzelfde principe dient te worden toegepast indien de reassurantie op meerjaarsposten op meerjaarsbasis wordt afgegeven. Ter verkrijging van een juiste presentatie van het solvabiliteitsrisico, dient de actiefrekening „Reeds afgegeven reassurantiepremie op onverdiende jaarfracties van meerjaarsposten" zichtbaar in de balans van de passiefrekening "Voorziening onverdiende jaarfracties van meerjaarsposten" te worden afgetrokken. De met reassuradeuren afgesloten reassurantiecontracten hebben namelijk veelal de bepaling, dat bij beëindiging van het contract de door reassuradeuren terug te betalen onverdiende reassurantiepremie zal worden vastgesteld op basis van $40 \%$ van de in de 4 voorafgaande $\mathrm{kwartalen}$ in rekening-courant met reassuradeuren uit hoofde van het betreffende contract geboekte reassurantiepremie.

\section{Betaalde schaden en "voorziening voor niet afgewikkelde schadeclaims"}

1. De term ,schadereserve” dient te worden vervangen door ,voorziening voor niet afgewikkelde schadeclaims". (Zie I sub 1.)

2. Om de volgende redenen is het voor het bedrijfsbeleid van groot belang om intern van de betaalde schaden een schadejarenstatistiek op te bouwen:

a. ter verkrijging tezamen met de in een jaar verdiende premie en rekening houdende met de uitstaande schaden, van een inzicht in de mate waarin de verschillende verzekeringsvormen, c.q. tussenpersonen, tot het resultaat hebben bijgedragen;

b. ter beoordeling, mogelijk zelfs als hulpmiddel ter vaststelling van de voorziening voor niet afgewikkelde schadeclaims.

3. De modellen van de staten welke periodiek bij de verzekeringskamer dienen te worden ingeleverd zullen nog nader bij algemene maatregel van bestuur worden vastgesteld. Het zou aanbeveling verdienen als verplicht voor te schrijven, staten welke voor Brand en Varia een schadejaar-en voor Transport een tekenjaarstatistiek geven. De verzekeringskamer zal door deze statistieken zich een 
beter oordeel kunnen vormen over de hoogte van de opgevoerde voorzieningen.

4. De nog veel verkondigde mening, dat het vaststellen van schadevoorzieningen een assurantietechnische aangelegenheid is, en de beoordeling buiten de deskundigheid van de controlerende accountant valt, lijkt mij niet juist.

$A$. Deze mening zal om te beginnen niet van toepassing kunnen zijn op alle onderdelen van de schadevoorziening waarbij men van de opgaven van derden afhankelijk is zoals bij pools, volmachten en maatschappijen (inzake afgegeven reassurantie), zie IV.

Door middel van afloopcontrole van de opgegeven schadevoorzieningen van voorgaande jaren (resp. van het lopend jaar) zal de accountant door eigen aanvullend onderzoek (zie ook IV) in staat zijn de juistheid en volledigheid van de eventueel noodzakelijke extra toevoegingen aan deze voorziening te beoordelen.

$B$. Wat betreft de controle op de volledigheid en juistheid van de schadevoorziening provinciale tekening (eigen afgegeven polissen) staan de accountant de volgende middelen ten dienste:

a. Vaststellen dat er in de organisatie een zodanig systeem bestaat dat alle aangemelde en nog niet betaalde schaden bij de schadevoorzieningvaststelling in aanmerking komen. De in het nieuwe jaar aangemelde schaden betrekking hebbende op het oude jaar dienen in aanmerking te worden genomen.

De goede werking van dit systeem beoordelen.

b. De hiervoren onder II sub 2 bedoelde schadejaarstatistiek stelt de accountant in staat om langs statistische weg de aanvaardbaarheid van de berekende schadevoorziening te toetsen.

c. De afloopcontrole van de schadevoorziening van het voorgaande jaar met een analyse van de eventuele verschillen zullen de accountant een inzicht geven in het systeem van berekening der voorziening voor niet afgewikkelde schaden.

$d$. De inmiddels in het nieuwe jaar betaalde schaden welke betrekking hebben op voorgaande jaren maken het mogelijk de juistheid van een gedeelte der schadevoorziening vast te stellen.

$e$. Bij de grote schaden waarbij juridische, medische of andere onzekerheden schattingen noodzakelijk maken, dienen deze schattingen in overleg met de behandelende advocaten resp. de medisch adviseur zo goed mogelijk plaats te vinden. Ook al blijkt achteraf dat deze schattingen te hoog of te laag zijn, is voldaan aan de eis dat de schadevoorziening volgens goed koopmansgebruik is vastgesteld. Bovendien zal tengevolge van het optreden van reassurantie (excess of loss, excedent) juist op deze grote schaden onzuiverheden in de schattingen weinig invloed op het resultaat hebben.

5. Regresvorderingen uit hoofde van betaalde schaden vormen een onderdeel waaraan bij de schadeverzekeringsbedrijven nog vaak onvoldoende aandacht wordt besteed.

Bijvoorbeeld worden casco-schaden op all-risk polissen uitbetaald voordat de schuldvraag vaststaat en in de gevallen dat de tegenpartij schuldig is, wordt vaak de schade eerst bij betaling door de tegenpartij teruggeboekt. 
Bovenstaand voorbeeld laat zien dat de organisatie op deze wijze onvoldoende waarborgen voor de volledige behandeling en ontvangst van alle regresvorderingen geeft. Het is daarom wenselijk dat:

a. uitbetaling van schaden voordat de schuldvraag vaststaat als voorschotten worden verantwoord;

b. op het moment dat de schuldvraag vaststaat een overboeking plaatsvindt hetzij naar regresvorderingen, hetzij naar schaden;

c. alle schadedossiers alvorens zij worden afgelegd door een daartoe aangewezen functionaris, een ander dan de schaderegelaar zijnde, worden geparafeerd na controle dat regres is uitgeoefend resp. geen regres kan worden uitgeoefend.

$\mathrm{Bij}$ de vaststelling van de voorziening voor niet afgewikkelde schadeclaims dient rekening te worden gehouden met het saldo van op voorschotten geboekte schaden, hetzij door het saldo voorschotten veiligheidshalve in het geheel, hetzij door een gedeelte statistisch dan wel door individuele beoordeling vastgesteld, aan de voorziening toe te voegen.

\section{Grondslagen van berekening Voorzieningen}

Mogelijk ligt het in de bedoeling, in ieder geval is het m.i. noodzakelijk, zowel bij de jaarrekening als bij de periodiek in te dienen staten, een verplichte staat in te voeren waarop per voorziening (zowel voor wat betreft de onverdiende premies als de niet afgewikkelde schadeclaims) en per schadevoorziening voor iedere afdeling (branche) de grondslagen van de berekening dienen te worden aangegeven en waarbij iedere af wijking in deze grondslagen ten opzichte van voorgaande jaren specifiek en gemotiveerd dient te worden vermeld, op zodanige wijze dat de invloed op de resultaten hieruit kan worden gekwantificeerd.

IV. Het standpunt van de accountant ten aanzien van de usance in de verzekeringswereld overeenkomsten te sluiten met binnen- en buitenlandse gevolmachtigde agenten op basis van vertrouwen

Het vertrouwen dat de leiding van een verzekeringsmaatschappij stelt in de gevolmachtigde agenten heeft o.m. betrekking op de volledigheid van de premieafdracht, de juistheid en volledigheid van de opgegeven schadevoorzieningen en de juistheid van de in rekening gebrachte schaden.

Dit vertrouwen kan voor de accountant belast met de certificering van de jaarrekening, indien de omvang der tekening via volmachten althans van enige betekenis is, geen aanleiding zijn dit gedeelte der tekening buiten zijn controle te laten. De accountant zal dan ook op grond van eigen arbeid, dan wel op grond van de verklaring van een medelid of buitenlandse accountant (zie art. 7 en 8 Reglement van Arbeid van het N.I.v.A.) op objectieve wijze dienen vast te stellen dat het subjectieve vertrouwen van de leiding in de juistheid en volledigheid van de door de gevolmachtigde agenten verantwoorde cijfers, is gerechtvaardigd. In deze gedachte is er van uitgegaan, dat de omvang van de bedrijven van de meeste gevolmachtigden zodanig is, dat er sprake kan zijn van een doelmatige interne organisatie en daarmee samenhangende functiescheiding, op grond waarvan deze volmachten als dan controleerbaar zijn.

In gevallen waarbij een maatschappij werkt met één of meer volmachten die niet controleerbaar zijn, zal de controlerende accountant op de jaarstukken resp. 
periodiek in te dienen staten, van deze maatschappij geen goedkeurende verklaring kunnen afgeven. Ook een goedkeurende verklaring met voorbehoud zal in dit geval niet kunnen worden afgegeven, daar de betekenis van het voorbehoud niet $\mathrm{kwantificeerbaar}$ is.

Ook met betrekking tot inkomende reassurantiecontracten kan worden gesteld, dat de accountant op grond van eigen arbeid, dan wel op grond van de verklaring van een medelid of buitenlandse accountant, tot een inzicht omtrent juistheid en volledigheid van de door deze afgevende maatschappijen verantwoorde cijfers dient te komen.

Deze inkomende reassurantie betreft de acceptatie van de afgifte van reassurantie van andere maatschappijen (zowel in het binnenland als in het buitenland). Daar de meeste landen een wettelijke regeling van het schadeverzekeringsbedrijf kennen, waarbij tevens sprake is van een verplichte accountantscontrole, zou een grote besparing in de accountantsarbeid kunnen worden verkregen indien alle controlerende accountants (zowel nationaal als internationaal) ten behoeve van de accepterende maatschappijen verklaringen zouden afgeven (omtrent juistheid van de afgegeven premie, schaden, voorzieningen, enz.) bij de afgevende maatschappijen (de gecontroleerde maatschappijen). 